\title{
A SYMMETRIC SOLUTION OF A MULTIPOINT BOUNDARY VALUE PROBLEM AT RESONANCE
}

NICKOLAI KOSMATOV

Received 18 January 2005; Accepted 1 June 2005

We apply a coincidence degree theorem of Mawhin to show the existence of at least one symmetric solution of the nonlinear second-order multipoint boundary value problem $u^{\prime \prime}(t)=f\left(t, u(t),\left|u^{\prime}(t)\right|\right), t \in(0,1), u(0)=\sum_{i=1}^{n} \mu_{i} u\left(\xi_{i}\right), u(1-t)=u(t), t \in[0,1]$, where $0<\xi_{1}<\xi_{2}<\cdots<\xi_{n} \leq 1 / 2, \sum_{i=1}^{n} \mu_{i}=1, f:[0,1] \times \mathbb{R}^{2} \rightarrow \mathbb{R}$ with $f(t, x, y)=f(1-t, x, y)$, $(t, x, y) \in[0,1] \times \mathbb{R}^{2}$, satisfying the Carathéodory conditions.

Copyright (C) 2006 Nickolai Kosmatov. This is an open access article distributed under the Creative Commons Attribution License, which permits unrestricted use, distribution, and reproduction in any medium, provided the original work is properly cited.

\section{Definitions and technical results}

We study symmetric solutions of the multipoint nonlinear boundary value problem

$$
\begin{gathered}
u^{\prime \prime}(t)=f\left(t, u(t),\left|u^{\prime}(t)\right|\right), \quad t \in(0,1), \\
u(0)=\sum_{i=1}^{n} \mu_{i} u\left(\xi_{i}\right) \\
u(1-t)=u(t), \quad t \in[0,1]
\end{gathered}
$$

where $\xi_{i} \in[0,1]$ with $0<\xi_{1}<\xi_{2}<\cdots<\xi_{n} \leq 1 / 2, \mu_{i} \in \mathbb{R}$ with

$$
\sum_{i=1}^{n} \mu_{i}=1
$$

and the inhomogeneous term satisfies

(H0) $f:[0,1] \times \mathbb{R}^{2} \rightarrow \mathbb{R}$ with

$$
f(t, x, y)=f(1-t, x, y), \quad(t, x, y) \in[0,1] \times \mathbb{R}^{2} .
$$


If there is a $\mu_{i}>1$, we assume, in addition, that

$$
\sum_{i=1}^{n} \mu_{i} \xi_{i}\left(1-\xi_{i}\right) \neq 0 .
$$

Due to the condition (1.4) the differential operator in the left side of (1.1) is not invertible. In the literature, boundary value problems of this type are referred to as problems at resonance. Boundary value problems at resonance have been studied by several authors including the most recent works $[1-9,11]$. In the recent works $[5,6,8,9]$, the inhomogeneous term is either a continuous function on $[0,1] \times \mathbb{R}^{2}$ or the sum of a continuous and a Lebesgue integrable functions. In this note, we merely require measurability of $f$ in the first variable, continuity in the rest of variables for $a$. $a$. values of $t$, and, in addition, $f$ being locally bounded by Lebesgue integrable functions for $a$. $a$. values of $t$. The above assumptions constitute the so-called Carathéodory conditions.

In this section, we provide the necessary background definitions and facts and state the key theorem due to Mawhin [10]. In the second section, we provide additional assumptions on the inhomogeneous term and give the sufficient conditions of existence of at least one solution of (1.1)-(1.3). The emphasis in this note is on symmetric solutions at resonance.

Definition 1.1. Let $X$ and $Z$ be normed spaces. A linear mapping $L: \operatorname{dom} L \subset X \rightarrow Z$ is called a Fredholm mapping if the following two conditions hold:

(i) $\operatorname{ker} L$ has a finite dimension,

(ii) $\operatorname{Im} L$ is closed and has a finite codimension.

If $L$ is a Fredholm mapping, its (Fredholm) index is the integer $\operatorname{Ind} L=\operatorname{dim} \operatorname{ker} L-$ $\operatorname{codim} \operatorname{Im} L$.

In this paper, we are concerned with a Fredholm mapping of index zero. From Definition 1.1, it follows that there exist continuous projectors $P: X \rightarrow X$ and $Q: Z \rightarrow Z$ such that

$$
\operatorname{Im} P=\operatorname{ker} L, \quad \operatorname{ker} Q=\operatorname{Im} L, \quad X=\operatorname{ker} L \oplus \operatorname{ker} P, \quad Z=\operatorname{Im} L \oplus \operatorname{Im} Q,
$$

and that the mapping

$$
\left.L\right|_{\operatorname{dom} L \cap \operatorname{ker} P}: \operatorname{dom} L \cap \operatorname{ker} P \longrightarrow \operatorname{Im} L
$$

is invertible. We denote the inverse of $\left.L\right|_{\operatorname{dom} L \cap \operatorname{ker} P}$ by $K_{P}: \operatorname{Im} L \rightarrow \operatorname{dom} L \cap \operatorname{ker} P$. The generalized inverse of $L$ denoted by $K_{P, Q}: Z \rightarrow \operatorname{dom} L \cap \operatorname{ker} P$ is defined by $K_{P, Q}=K_{P}(I-Q)$.

If $L$ is a Fredholm mapping of index zero, then for every isomorphism $J: \operatorname{Im} Q \rightarrow \operatorname{ker} L$, the mapping $J Q+K_{P, Q}: Z \rightarrow \operatorname{dom} L$ is an isomorphism and, for every $u \in \operatorname{dom} L$,

$$
\left(J Q+K_{P, Q}\right)^{-1} u=\left(L+J^{-1} P\right) u .
$$

Definition 1.2. Let $L: \operatorname{dom} L \subset X \rightarrow Z$ be a Fredholm mapping, let $E$ be a metric space, and let $N: E \rightarrow Z$ be a mapping. Say that $N$ is $L$-compact on $E$ if $Q N: E \rightarrow Z$ and $K_{P, Q} N$ : $E \rightarrow X$ are compact on $E$. In addition, say that $N$ is $L$-completely continuous if it is $L$ compact on every bounded $E \subset X$. 
When the boundary value problem is shown to be equivalent to the abstract equation $L u=N u$, the existence of a solution will be guaranteed by the following theorem due to Mawhin [10, Theorem IV.13].

Theorem 1.3. Let $\Omega \subset X$ be open and bounded, L be a Fredholm mapping of index zero, and let $N$ be L-compact on $\bar{\Omega}$. Assume that the following conditions are satisfied:

(i) $L u \neq \lambda N u$ for every $(u, \lambda) \in((\operatorname{dom} L \backslash \operatorname{ker} L) \cap \partial \Omega) \times(0,1)$;

(ii) $N u \notin \operatorname{Im} L$ for every $u \in \operatorname{ker} L \cap \partial \Omega$;

(iii) $\operatorname{deg}\left(\left.Q N\right|_{\operatorname{ker} L \cap \partial \Omega}, \Omega \cap \operatorname{ker} L, 0\right) \neq 0$, with $Q: Z \rightarrow Z$ a continuous projector such that $\operatorname{ker} Q=\operatorname{Im} L$.

Then the equation $L u=N u$ has at least one solution in $\operatorname{dom} L \cap \bar{\Omega}$.

The following definition introduces the so-called Carathéodory conditions imposed on a map.

Definition 1.4. Say that the map $f:[0,1] \times \mathbb{R}^{n} \rightarrow \mathbb{R},(t, z) \mapsto f(t, z)$ satisfies the Carathéodory conditions with respect to $L^{1}[0,1]$ if the following conditions are satisfied:

(i) for each $z \in \mathbb{R}^{n}$, the mapping $t \mapsto f(t, z)$ is Lebesgue measurable;

(ii) for almost each $t \in[0,1]$, the mapping $z \mapsto f(t, z)$ is continuous on $\mathbb{R}^{n}$;

(iii) for each $r>0$, there exists $\alpha_{r} \in L^{1}([0,1], \mathbb{R})$ such that for a.e. $t \in[0,1]$ and every $z$ such that $|z| \leq r,|f(t, z)| \leq \alpha_{r}(t)$.

We introduce the Sobolev space

$W^{2,1}(0,1)=\left\{u:[0,1] \longrightarrow \mathbb{R}: u, u^{\prime}\right.$ absolutely continuous on $[0,1]$ and $\left.u^{\prime \prime} \in L[0,1]\right\}$

Let $X=C^{1}[0,1]$ with the norm $\|u\|=\max \left\{\|u\|_{\infty},\left\|u^{\prime}\right\|_{\infty}\right\}$ and $Z=L^{1}[0,1]$ with the usual Lebesgue norm denoted by $\|\cdot\|_{1}$. Consider the mapping $L: \operatorname{dom} L \subset X \rightarrow Z$ with

$$
\operatorname{dom} L=\left\{u \in W^{2,1}(0,1): u \text { satisfies (1.2) and (1.3) }\right\}
$$

by

$$
L u(t)=u^{\prime \prime}(t), \quad t \in(0,1)
$$

Define the mapping $N: X \rightarrow Z$ by

$$
N u(t)=f\left(t, u(t),\left|u^{\prime}(t)\right|\right), \quad t \in(0,1) .
$$

Lemma 1.5. The mapping $L: \operatorname{dom} L \subset X \rightarrow Z$ is a Fredholm mapping of index zero.

Proof. It is clear that $\operatorname{ker} L=\mathbb{R}$.

Let $u \in \operatorname{dom} L$ and consider the linear equation

$$
u^{\prime \prime}(t)=g(t)
$$


4 A symmetric solution of a multipoint boundary value

subject to (1.2), (1.3). Then $g \in Z$ is symmetric on the interval $[0,1]$. Since $u^{\prime}$ is absolutely continuous, it follows from the symmetry condition (1.3) that

$$
u^{\prime}(t)=\int_{0}^{t} g(s) d s-\int_{0}^{1}(1-s) g(s) d s
$$

Integrating again, we get

$$
u(t)=\int_{0}^{t}(t-s) g(s) d s-t \int_{0}^{1}(1-s) g(s) d s+c .
$$

Since $\sum_{i=1}^{n} \mu_{i}=1$, it follows from (1.2) that we must have

$$
\sum_{i=1}^{n}\left(\mu_{i} \int_{0}^{\xi_{i}}\left(\xi_{i}-s\right) g(s) d s-\mu_{i} \xi_{i} \int_{0}^{1}(1-s) g(s) d s\right)=0 .
$$

Conversely, if (1.17) holds for some $g \in Z$, we take the candidate of $u \in \operatorname{dom} L$ as given by (1.16) and establish that it is symmetric, absolutely continuous along with its derivative, $u^{\prime \prime}(t)=g(t)$ for $a$. a. $t \in(0,1)$ and (1.2) is satisfied. In fact, we have

$$
\operatorname{Im} L=\{g \in Z: g \text { satisfies (1.3) and (1.17) }\}
$$

We recall the condition (1.6) and define the continuous linear mapping $Q: Z \rightarrow Z$ by

$$
Q g=\frac{2}{\sum_{i=1}^{n} \mu_{i} \xi_{i}\left(1-\xi_{i}\right)} \sum_{i=1}^{n}\left(\mu_{i} \xi_{i} \int_{0}^{1}(1-s) g(s) d s-\mu_{i} \int_{0}^{\xi_{i}}\left(\xi_{i}-s\right) g(s) d s\right) .
$$

It is easy to see that $Q^{2} g=Q g$ for all $g \in Z$, that is, the mapping $Q$ is idempotent. Observe also that (1.17) and (1.19) imply that $\operatorname{Im} L=\operatorname{ker} Q$. Take $g \in Z$ in the form $g=(g-Q g)+$ $Q g$ so that $g-Q g \in \operatorname{Im} L$ and $Q g \in \mathbb{R}$. If $g \equiv c \neq 0$, then, by (1.6), $Q g \neq 0$, which implies that $\operatorname{Im} L \cap \mathbb{R}=\{0\}$. Hence $Z=\operatorname{Im} L \oplus \mathbb{R}$.

Now, $\operatorname{Ind} L=\operatorname{dim} \operatorname{ker} L-\operatorname{codim} \operatorname{Im} L=0$ and so $L$ is a Fredholm mapping of index zero.

The continuous projector $P: X \rightarrow X$ is defined by

$$
P u(t)=u(0), \quad t \in(0,1) .
$$

By taking $u \in X$ in the form $u(t)=u(0)+(u(t)-u(0))$, it is clear that $X=\operatorname{ker} L \oplus \operatorname{ker} P$. Note that the projectors $P$ and $Q$ are exact, that is, satisfy the relationships (1.7). Define $K_{P}: \operatorname{Im} L \rightarrow \operatorname{dom} L \cap \operatorname{ker} P$ by

$$
K_{P} g(t)=\int_{0}^{t}(t-s) g(s) d s-t \int_{0}^{1}(1-s) g(s) d s,
$$

so that

$$
\left(K_{P} g(t)\right)^{\prime}=\int_{0}^{t} g(s) d s-\int_{0}^{1}(1-s) g(s) d s .
$$


Then $\left\|K_{P} g\right\|_{\infty} \leq 2\|g\|_{1}$ and $\left\|\left(K_{P} g\right)^{\prime}\right\|_{\infty} \leq 2\|g\|_{1}$, and thus

$$
\left\|K_{P} g\right\| \leq 2\|g\|_{1} .
$$

In fact if $g \in \operatorname{Im} L$, then

$$
\left(L K_{P}\right) g(t)=\frac{d^{2}}{d t^{2}}\left(\int_{0}^{t}(t-s) g(s) d s-t \int_{0}^{1}(1-s) g(s) d s\right)=g(t) .
$$

Also, if $u \in \operatorname{dom} L \cap \operatorname{ker} P$, then

$$
\left(K_{P} L\right) u(t)=\int_{0}^{t}(t-s) u^{\prime \prime}(s) d s-t \int_{0}^{1}(1-s) u^{\prime \prime}(s) d s=u(t)-u(0)-t(u(1)-u(0))=u(t)
$$

(since $u \in \operatorname{ker} P$ and $u$ is symmetric, $u(0)=u(1)=0$ ). Thus, we get that

$$
K_{P}=\left(\left.L\right|_{\operatorname{dom} L \cap \operatorname{ker} P}\right)^{-1} \text {. }
$$

For convenience, we introduce a constant

$$
C=\frac{2}{\sum_{i=1}^{n} \mu_{i} \xi_{i}\left(1-\xi_{i}\right)} .
$$

Now

$$
\begin{aligned}
Q N u= & C \sum_{i=1}^{n}\left(\mu_{i} \xi_{i} \int_{0}^{1}(1-s) f\left(s, u(s),\left|u^{\prime}(s)\right|\right) d s-\mu_{i} \int_{0}^{\xi_{i}}\left(\xi_{i}-s\right) f\left(s, u(s),\left|u^{\prime}(s)\right|\right) d s\right), \\
K_{P, Q} N u(t)= & \int_{0}^{t}(t-s) N u(s) d s-t \int_{0}^{1}(1-s) N u(s) d s \\
& -\int_{0}^{t}(t-s)(Q N) u(s) d s+t \int_{0}^{1}(1-s)(Q N) u(s) d s \\
= & \int_{0}^{t}(t-s) f\left(s, u(s),\left|u^{\prime}(s)\right|\right) d s-t \int_{0}^{1}(1-s) f\left(s, u(s),\left|u^{\prime}(s)\right|\right) d s \\
& -\frac{1}{2} C t(t-1) \sum_{i=1}^{n}\left(\mu_{i} \xi_{i} \int_{0}^{1}(1-s) f\left(s, u(s),\left|u^{\prime}(s)\right|\right) d s\right. \\
& \left.-\mu_{i} \int_{0}^{\xi_{i}}\left(\xi_{i}-s\right) f\left(s, u(s),\left|u^{\prime}(s)\right|\right) d s\right) .
\end{aligned}
$$

Lemma 1.6. The mapping $N$ is L-completely continuous.

Proof. Let $E \subset X$ be bounded and $\left\{u_{k}\right\} \subset E$. Define the sequence $\left\{v_{k}\right\}$ by $v_{k}(t)=K_{P, Q} N u_{k}(t)$. Set

$$
r=\sup \{\|u\|: u \in E\}
$$


6 A symmetric solution of a multipoint boundary value

Since the function $f:[0,1] \times \mathbb{R}^{2} \rightarrow \mathbb{R}$ satisfies the Carathéodory conditions with respect to $L^{1}[0,1]$, there exists a Lebesgue integrable function $\alpha_{r}$ such that for all $k \in \mathbb{N}$ and a.e. $t \in[0,1]$

$$
\left|N u_{k}(t)\right|=\left|f\left(t, u_{k}(t),\left|u_{k}^{\prime}(t)\right|\right)\right| \leq \alpha_{r}(t) .
$$

For $t \in[0,1]$ and $k \in \mathbb{N}$,

$$
\begin{aligned}
\left|v_{k}(t)\right|= & \left|K_{P}(I-Q) N u_{k}(t)\right| \\
= & \mid \int_{0}^{t}(t-s) N u_{k}(s) d s-t \int_{0}^{1}(1-s) N u_{k}(s) d s \\
& -\frac{1}{2} C t(t-1) \sum_{i=1}^{n}\left(\mu_{i} \xi_{i} \int_{0}^{1}(1-s) N u_{k}(s) d s-\mu_{i} \int_{0}^{\xi_{i}}\left(\xi_{i}-s\right) N u_{k}(s) d s\right) \mid \\
\leq & \int_{0}^{t}(t-s)\left|N u_{k}(s)\right| d s+t \int_{0}^{1}(1-s)\left|N u_{k}(s)\right| d s \\
& +\frac{1}{2} C|t(t-1)| \sum_{i=1}^{n}\left(\mu_{i} \xi_{i} \int_{0}^{1}(1-s)\left|N u_{k}(s)\right| d s+\mu_{i} \int_{0}^{\xi_{i}}\left(\xi_{i}-s\right)\left|N u_{k}(s)\right| d s\right) \\
\leq & \left(1+\frac{C}{8} \sum_{i=1}^{n} \mu_{i} \xi_{i}\left(1+\xi_{i}\right)\right)\left\|\alpha_{r}\right\|_{1},
\end{aligned}
$$

that is, the sequence $\left\{v_{k}\right\}$ is uniformly bounded on $[0,1]$.

Now

$$
\begin{aligned}
\left|v_{k}^{\prime}(t)\right|= & \mid \int_{0}^{t} N u_{k}(s) d s-\int_{0}^{1}(1-s) N u_{k}(s) d s \\
& \quad-\frac{1}{2} C(2 t-1) \sum_{i=1}^{n}\left(\mu_{i} \xi_{i} \int_{0}^{1}(1-s) N u_{k}(s) d s-\mu_{i} \int_{0}^{\xi_{i}}\left(\xi_{i}-s\right) N u_{k}(s) d s\right) \mid \\
\leq & \int_{0}^{t}\left|N u_{k}(s)\right| d s+\int_{0}^{1}(1-s)\left|N u_{k}(s)\right| d s \\
& +\frac{1}{2} C|2 t-1| \sum_{i=1}^{n}\left(\mu_{i} \xi_{i} \int_{0}^{1}(1-s)\left|N u_{k}(s)\right| d s+\mu_{i} \int_{0}^{\xi_{i}}\left(\xi_{i}-s\right)\left|N u_{k}(s)\right| d s\right) \\
\leq & \frac{1}{2}\left(3+C \sum_{i=1}^{n} \mu_{i} \xi_{i}\left(1+\xi_{i}\right)\right)\left\|\alpha_{r}\right\|_{1}
\end{aligned}
$$

for all $t \in[0,1]$ and $k \in \mathbb{N}$, that is, the sequence $\left\{v_{k}^{\prime}\right\}$ is uniformly bounded on $[0,1]$ and as such is equicontinuous on $[0,1]$. Since $\left\{v_{k}\right\}$ is uniformly bounded and equicontinuous on $[0,1]$, by Arzela-Ascoli theorem, it has a subsequence $\left\{v_{k_{l}}\right\}$ that converges to some $v \in C[0,1]$. 
Consider the sequence $\left\{w_{k_{l}}\right\}$ defined by

$$
\begin{aligned}
w_{k_{l}}(t)= & \frac{d}{d t} K_{P}(I-Q) N u_{k_{l}}(t) \\
= & \int_{0}^{t} N u_{k_{l}}(s) d s-\int_{0}^{1}(1-s) N u_{k_{l}}(s) d s \\
& -\frac{1}{2} C(2 t-1) \sum_{i=1}^{n}\left(\mu_{i} \xi_{i} \int_{0}^{1}(1-s) N u_{k_{l}}(s) d s+\mu_{i} \int_{0}^{\xi_{i}}\left(\xi_{i}-s\right) N u_{k_{l}}(s) d s\right) .
\end{aligned}
$$

Employing arguments similar to that for $\left\{v_{k}\right\}$ one can show that $\left\{w_{k_{l}}\right\}$ is uniformly bounded and equicontinuous on $[0,1]$. Hence $\left\{w_{k_{l}}\right\}$ as a subsequence that converges to some $w \in C[0,1]$. In fact, $w(t)=v^{\prime}(t), t \in[0,1]$ and, thus, there is a subsequence of $\left\{v_{k_{l}}\right\}$ that converges in $C^{1}[0,1]$. Therefore, the image of $E$ under $K_{P, Q} N$ is relatively compact. Since the function $f:[0,1] \times \mathbb{R}^{2} \rightarrow \mathbb{R}$ satisfies the Carathéodory conditions with respect to $L^{1}[0,1]$, the continuity of $K_{P, Q} N$ on $E$ follows from the Lebesgue dominated convergence theorem.

Similar considerations apply to show that $Q N$ is continuous and that $Q N(E)$ is relatively compact. Now, since the mappings $Q N$ and $K_{P, Q} N$ are compact on an arbitrary bounded $E \subset X$, the mapping $N: X \rightarrow Z$ is $L$-completely continuous by Definition 1.2.

\section{Solutions at resonance}

Assume that the following conditions on the function $f\left(t, x_{1},\left|x_{2}\right|\right)$ are satisfied:

(H1) there exists a constant $A>0$ such that for each $u \in \operatorname{dom} L \backslash \operatorname{ker} L$ satisfying $|u(t)|$ $>A$ for all $t \in[0,1]$, we have

$$
\sum_{i=1}^{n}\left(\mu_{i} \xi_{i} \int_{0}^{1}(1-s) f\left(s, u(s),\left|u^{\prime}(s)\right|\right) d s-\mu_{i} \int_{0}^{\xi_{i}}\left(\xi_{i}-s\right) f\left(s, u(s),\left|u^{\prime}(s)\right|\right) d s\right) \neq 0
$$

(H2) there exist functions $\alpha, \beta, \gamma, \rho \in L^{1}[0,1]$ and a constant $\epsilon \in[0,1)$ such that for all $\left(x_{1}, x_{2}\right) \in \mathbb{R}^{2}$ and a.e. $t \in[0,1]$, we have either

$$
\left|f\left(t, x_{1},\left|x_{2}\right|\right)\right| \leq \rho(t)+\alpha(t)\left|x_{1}\right|+\beta(t)\left|x_{2}\right|+\gamma(t)\left|x_{1}\right|^{\epsilon}
$$

or

$$
\left|f\left(t, x_{1},\left|x_{2}\right|\right)\right| \leq \rho(t)+\alpha(t)\left|x_{1}\right|+\beta(t)\left|x_{2}\right|+\gamma(t)\left|x_{2}\right|^{\epsilon}
$$

(H3) there exists a constant $B>0$ such that for every $c \in \mathbb{R}$ with $|c|>B$, we have either

$$
c \sum_{i=1}^{n}\left(\mu_{i} \xi_{i} \int_{0}^{1}(1-s) f(s, c, 0) d s-\mu_{i} \int_{0}^{\xi_{i}}\left(\xi_{i}-s\right) f(s, c, 0) d s\right)<0
$$

or

$$
c \sum_{i=1}^{n}\left(\mu_{i} \xi_{i} \int_{0}^{1}(1-s) f(s, c, 0) d s-\mu_{i} \int_{0}^{\xi_{i}}\left(\xi_{i}-s\right) f(s, c, 0) d s\right)>0 .
$$


8 A symmetric solution of a multipoint boundary value

Theorem 2.1. If (HO)-(H3) hold, then the boundary value problem (1.1)-(1.3) has at least one solution provided that

$$
\|\alpha\|_{1}+\|\beta\|_{1}<\frac{2}{5}
$$

Proof. We construct an open bounded set $\Omega \subset X$ that satisfies the assumptions of Theorem 1.3. Let

$$
\Omega_{1}=\{u \in \operatorname{dom} L \backslash \operatorname{ker} L: L u=\lambda N u \text { for some } \lambda \in(0,1)\}
$$

For $u \in \Omega_{1}$, we have $u \notin \operatorname{ker} L, \lambda \neq 0$ and $N u \in \operatorname{Im} L$. But $\operatorname{ker} Q=\operatorname{Im} L$ and, thus,

$$
\sum_{i=1}^{n}\left(\mu_{i} \xi_{i} \int_{0}^{1}(1-s) f\left(s, u(s),\left|u^{\prime}(s)\right|\right) d s-\mu_{i} \int_{0}^{\xi_{i}}\left(\xi_{i}-s\right) f\left(s, u(s),\left|u^{\prime}(s)\right|\right) d s\right)=0
$$

since $Q N u=0$. It follows from $(\mathrm{H} 1)$ that there exists $t_{0} \in[0,1]$ such that $\left|u\left(t_{0}\right)\right| \leq A$. Now,

$$
|u(0)|=\left|u\left(t_{0}\right)-\int_{0}^{t_{0}} u^{\prime}(s) d s\right| \leq\left|u\left(t_{0}\right)\right|+\int_{0}^{t_{0}}\left|u^{\prime}(s)\right| d s \leq A+\left\|u^{\prime}\right\|_{\infty} .
$$

Also, since $u^{\prime}$ is absolutely continuous, and, by symmetry, $u^{\prime}(1 / 2)=0, u^{\prime \prime}(1-t)=u^{\prime \prime}(t)$,

$$
u^{\prime}(t)=-\int_{t}^{1 / 2} u^{\prime \prime}(s) d s
$$

Hence

$$
\left\|u^{\prime}\right\|_{\infty} \leq \frac{1}{2}\left\|u^{\prime \prime}\right\|_{1}=\frac{1}{2}\|L u\|_{1}<\frac{1}{2}\|N u\|_{1} .
$$

Combining the above inequalities, we get

$$
|u(0)|<A+\frac{1}{2}\|N u\|_{1}
$$

Observe that $(I-P) u \in \operatorname{Im} K_{P}=\operatorname{dom} L \cap \operatorname{ker} P$ for $u \in \Omega_{1}$. Then, by (1.23) and (1.26),

$$
\|(I-P) u\|=\left\|K_{P} L(I-P) u\right\| \leq 2\|L(I-P) u\|_{1}=2\|L u\|_{1}<2\|N u\|_{1} .
$$

Using (2.12) and (2.13), we obtain

$$
\|u\|=\|P u+(I-P) u\| \leq\|P u\|+\|(I-P) u\|<|u(0)|+2\|N u\|_{1}<A+\frac{5}{2}\|N u\|_{1},
$$

that is, for all $u \in \Omega_{1}$,

$$
\|u\|<A+\frac{5}{2}\|N u\|_{1}
$$


If the second condition of $(\mathrm{H} 2)$ is satisfied, then

$$
\|u\|_{\infty},\left\|u^{\prime}\right\|_{\infty} \leq\|u\| \leq \frac{5}{2}\left(\|\rho\|_{1}+\|\alpha\|_{1}\|u\|_{\infty}+\|\beta\|_{1}\left\|u^{\prime}\right\|_{\infty}+\|\gamma\|_{1}\left\|u^{\prime}\right\|_{\infty}^{\epsilon}\right)+A
$$

and consequently,

$$
\|u\|_{\infty} \leq \frac{5}{2-5\|\alpha\|_{1}}\left(\|\rho\|_{1}+\|\beta\|_{1}\left\|u^{\prime}\right\|_{\infty}+\|\gamma\|_{1}\left\|u^{\prime}\right\|_{\infty}^{\epsilon}+\frac{2 A}{5}\right)
$$

or

$$
\|u\|_{\infty} \leq \frac{5\|\beta\|_{1}}{2-5\|\alpha\|_{1}}\left\|u^{\prime}\right\|_{\infty}+\frac{5\|\gamma\|_{1}}{2-5\|\alpha\|_{1}}\left\|u^{\prime}\right\|_{\infty}^{\epsilon}+\frac{5\|\rho\|_{1}+2 A}{2-5\|\alpha\|_{1}} .
$$

Also, by (2.16) and (2.17),

$$
\begin{aligned}
\left\|u^{\prime}\right\|_{\infty} & \leq \frac{5}{2}\|\alpha\|_{1}\|u\|_{\infty}+\frac{5}{2}\left(\|\rho\|_{1}+\|\beta\|_{1}\left\|u^{\prime}\right\|_{\infty}+\|\gamma\|_{1}\left\|u^{\prime}\right\|_{\infty}^{\epsilon}+\frac{2 A}{5}\right) \\
& \leq \frac{5\|\beta\|_{1}}{2-5\|\alpha\|_{1}}\left\|u^{\prime}\right\|_{\infty}+\frac{5\|\gamma\|_{1}}{2-5\|\alpha\|_{1}}\left\|u^{\prime}\right\|_{\infty}^{\epsilon}+\frac{5\|\rho\|_{1}+2 A}{2-5\|\alpha\|_{1}}
\end{aligned}
$$

that is,

$$
\left\|u^{\prime}\right\|_{\infty} \leq \frac{5\|\gamma\|_{1}}{2-5\left(\|\alpha\|_{1}+\|\beta\|_{1}\right)}\left\|u^{\prime}\right\|_{\infty}^{\epsilon}+\frac{5\|\rho\|_{1}+2 A}{2-5\left(\|\alpha\|_{1}+\|\beta\|_{1}\right)} .
$$

But $\epsilon \in[0,1)$ and $\|\alpha\|_{1}+\|\beta\|_{1}<2 / 5$, so there exists $M_{1}>0$ such that $\left\|u^{\prime}\right\|_{\infty} \leq M_{1}$ for all $u \in \Omega_{1}$. The inequality (2.18) then shows that there exists $M_{2}>0$ such that $\|u\|_{\infty} \leq M_{2}$ for all $u \in \Omega_{1}$. Therefore, $\Omega_{1}$ is bounded given the second condition of (H2). If, otherwise, the first part of (H2) holds, then with minor adjustments to the arguments above we derive the same conclusion.

Define

$$
\Omega_{2}=\{u \in \operatorname{ker} L: N u \in \operatorname{Im} L\}
$$

Then $u \equiv c \in \mathbb{R}$ and

$$
N u \in \operatorname{Im} L=\operatorname{ker} Q
$$

imply that

$$
\sum_{i=1}^{n}\left(\mu_{i} \xi_{i} \int_{0}^{1}(1-s) f(s, c, 0) d s-\mu_{i} \int_{0}^{\xi_{i}}\left(\xi_{i}-s\right) f(s, c, 0) d s\right)=0 .
$$

Hence, by (H3),

$$
\|u\|=c \leq B,
$$

that is, $\Omega_{2}$ is bounded. 
We take our isomorphism, $J$, to be the identity map $I d: \operatorname{ker} L \rightarrow \operatorname{Im} L$, that is, $J c=c$ for $c \in \mathbb{R}$. Set

$$
\Omega_{3}=\{u \in \operatorname{ker} L:-\lambda J u+(1-\lambda) Q N u=0, \lambda \in[0,1]\}
$$

For every $c \in \Omega_{3}$,

$$
\lambda c=(1-\lambda) \sum_{i=1}^{n}\left(\mu_{i} \xi_{i} \int_{0}^{1}(1-s) f(s, c, 0) d s-\mu_{i} \int_{0}^{\xi_{i}}\left(\xi_{i}-s\right) f(s, c, 0) d s\right) .
$$

If $\lambda=1$, then $c=0$ and in the case $\lambda \in[0,1)$, if $|c|>B$, then by (H3),

$$
\lambda c^{2}=(1-\lambda) c \sum_{i=1}^{n}\left(\mu_{i} \xi_{i} \int_{0}^{1}(1-s) f(s, c, 0) d s-\mu_{i} \int_{0}^{\xi_{i}}\left(\xi_{i}-s\right) f(s, c, 0) d s\right)<0
$$

which, in either case, is a contradiction. If the other part of $(\mathrm{H} 3)$ is satisfied, then we take

$$
\Omega_{3}=\{u \in \operatorname{ker} L: \lambda J u+(1-\lambda) Q N u=0, \lambda \in[0,1]\}
$$

and, again, obtain a contradiction. Thus, in either case $\|u\|=c \leq B$ for all $u \in \Omega_{3}$, that is, $\Omega_{3}$ is bounded.

Let $\Omega$ be open and bounded such that $\bigcup_{i=1}^{3} \bar{\Omega}_{i} \subset \Omega$. Then the assumptions (i) and (ii) of Theorem 1.3 are fulfilled. By Definition 1.2, the mapping $N$ is $L$-compact on $\bar{\Omega}$. Lemma 1.5 establishes that $L$ is Fredholm of index zero. It only remains to verify that the third assumption of Theorem 1.3 applies.

We apply the degree property of invariance under a homotopy. To this end, we define a homotopy

$$
H(u, \lambda)= \pm \lambda J u+(1-\lambda) Q N u
$$

If $u \in \operatorname{ker} L \cap \partial \Omega$, then

$$
\begin{aligned}
\operatorname{deg}\left(\left.Q N\right|_{\operatorname{ker} L \cap \partial \Omega}, \Omega \cap \operatorname{ker} L, 0\right) & =\operatorname{deg}(H(\cdot, 0), \Omega \cap \operatorname{ker} L, 0) \\
& =\operatorname{deg}(H(\cdot, 1), \Omega \cap \operatorname{ker} L, 0) \\
& =\operatorname{deg}( \pm J, \Omega \cap \operatorname{ker} L, 0) \\
& \neq 0,
\end{aligned}
$$

so, the third assumption of Theorem 1.3 is fulfilled and the proof is complete.

\section{Acknowledgment}

The author wishes to thank the anonymous referee for the comments and suggestions on improving the presentation of the paper. 


\section{References}

[1] W. Feng and J. R. L. Webb, Solvability of three point boundary value problems at resonance, Nonlinear Analysis. Theory, Methods \& Applications. An International Multidisciplinary Journal. Series A: Theory and Methods 30 (1997), no. 6, 3227-3238.

[2] C. P. Gupta, A second order m-point boundary value problem at resonance, Nonlinear Analysis. Theory, Methods \& Applications. An International Multidisciplinary Journal. Series A: Theory and Methods 24 (1995), no. 10, 1483-1489.

[3] __ Existence theorems for a second order m-point boundary value problem at resonance, International Journal of Mathematics and Mathematical Sciences 18 (1995), no. 4, 705-710.

[4] __ Solvability of a multi-point boundary value problem at resonance, Results in Mathematics. Resultate der Mathematik 28 (1995), no. 3-4, 270-276.

[5] B. Liu, Solvability of multi-point boundary value problem at resonance. II, Applied Mathematics and Computation 136 (2003), no. 2-3, 353-377.

[6] Solvability of multi-point boundary value problem at resonance. IV, Applied Mathematics and Computation 143 (2003), no. 2-3, 275-299.

[7] Y. Liu and W. Ge, Solvability of a $(P, N-P)$-type multi-point boundary-value problem for higherorder differential equations, Electronic Journal of Differential Equations 2003 (2003), no. 120, $1-19$.

[8] B. Liu and J. S. Yu, Solvability of multi-point boundary value problem at resonance. III, Applied Mathematics and Computation 129 (2002), no. 1, 119-143.

[9] Solvability of multi-point boundary value problems at resonance. I, Indian Journal of Pure and Applied Mathematics 33 (2002), no. 4, 475-494.

[10] J. Mawhin, Topological Degree Methods in Nonlinear Boundary Value Problems, CBMS Regional Conference Series in Mathematics, vol. 40, American Mathematical Society, Rhode Island, 1979.

[11] X. Ni and W. Ge, Multi-point boundary-value problems for the p-Laplacian at resonance, Electronic Journal of Differential Equations 2003 (2003), no. 112, 1-7.

Nickolai Kosmatov: Department of Mathematics and Statistics, University of Arkansas at Little Rock, Little Rock, AR 72204-1099, USA

E-mail address: nxkosmatov@ualr.edu 


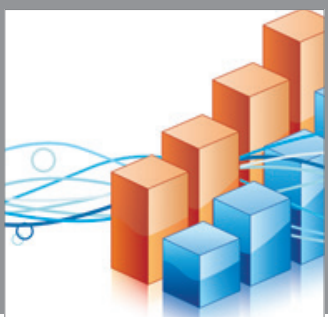

Advances in

Operations Research

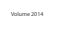

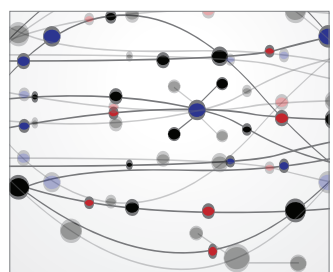

\section{The Scientific} World Journal
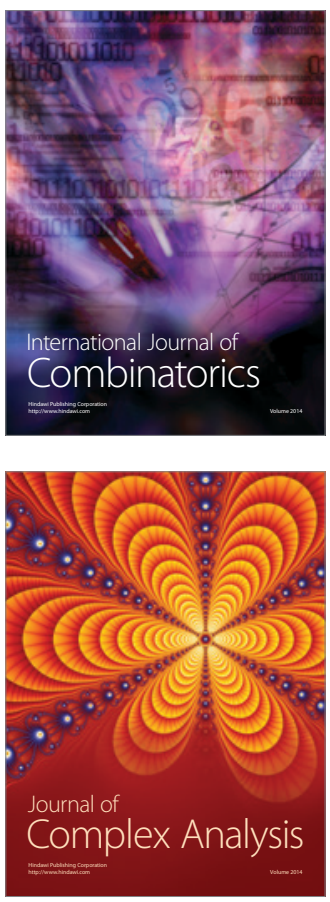

International Journal of

Mathematics and

Mathematical

Sciences
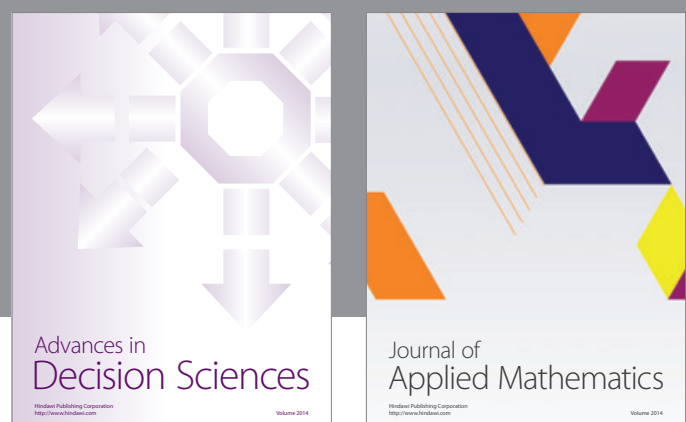

Journal of

Applied Mathematics
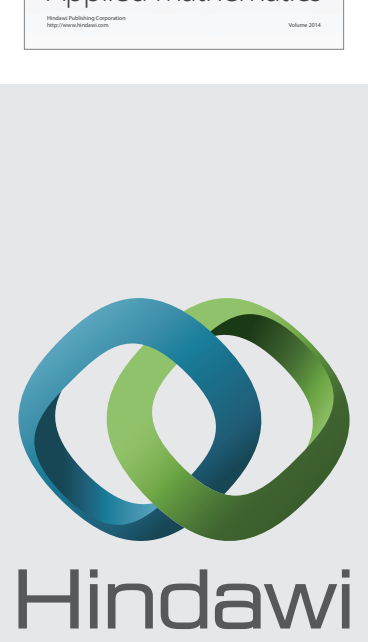

Submit your manuscripts at http://www.hindawi.com
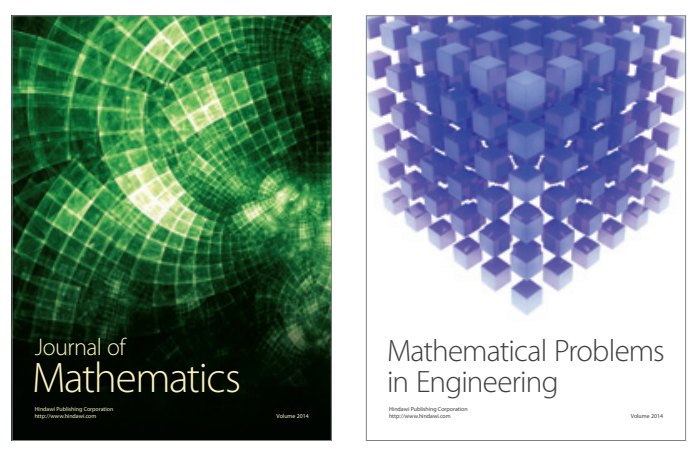

Mathematical Problems in Engineering
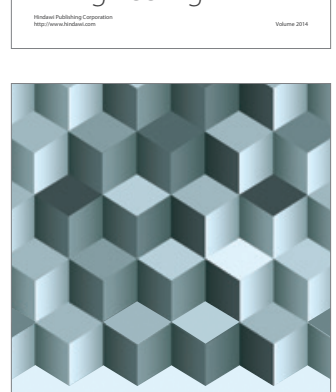

Journal of

Function Spaces
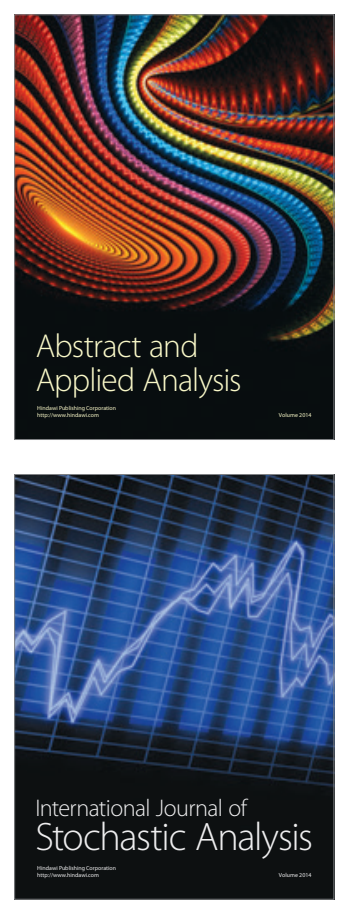

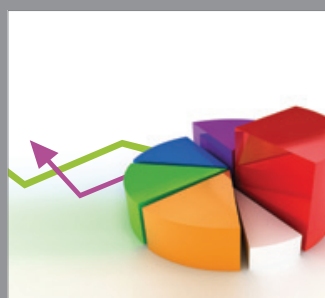

ournal of

Probability and Statistics

Promensencen
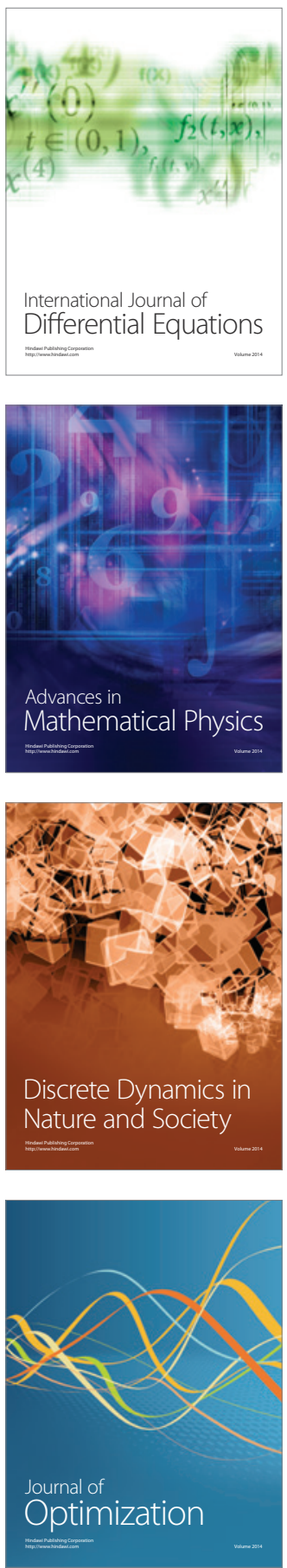